Thorax (1960), 15, 37.

\title{
SUBCUTANEOUS GAS EQUILIBRATION IN CLINICAL PRACTICE
}

\author{
BY \\ PAUL FORGACS \\ From the Brook General Hospital, Shooters Hill, London
}

(RECEIVED FOR PUBLICATION JULY 20, 1959)

When surgical emphysema is deliberately induced by injecting air under the skin, it exchanges gas with the tissues until the partial pressures of oxygen and carbon dioxide in the subcutaneous bubbles and the surrounding tissue fluids are nearly equal. Samples drawn from such a gas depot were first analysed by Leconte and Demarquay (1859) and the method was later applied by other physiologists to experimental studies on animals and man (Bazett and Sribyatta, 1928 ; Campbell, 1931 ; Meyer, 1935 ; Seevers, 1936). Clinical use of subcutaneous gas equilibration has not been reported previously. Experience with this technique during the past two years has shown that it is a convenient way of measuring the partial pressure of carbon dioxide in the tissue fluids in patients with respiratory disabilities.

\section{METHOD}

Air filtered through cotton-wool is drawn into a $10 \mathrm{ml}$. syringe fitted with a two-way tap and is injected into the subcutaneous tissue on the dorsal aspect of the forearm, having first ascertained that the needle is not in a vein. The amount of air injected depends on the length of time for which the gas depot is to be maintained. A depot of $50 \mathrm{ml}$. yields several samples during the next 12 hours, but a larger volume, up to $100 \mathrm{ml}$., is more easily located on the following day and can be replenished for further use if necessary.

The pressure in the subcutaneous gas depot is between 5 and $10 \mathrm{~cm}$. $\mathrm{H}_{2} \mathrm{O}$ immediately after the injection. The air remains in a single compartment for a short time only and soon disperses into small bubbles in the superficial fascia and fat of the forearm at a depth of 2 to $10 \mathrm{~mm}$. (Fig. 1). Samples of 1 to $3 \mathrm{ml}$. can, however, be withdrawn even after some hours from sites where the tissues are loose and contain little fat. The dorsal aspect of the forearm satisfies these conditions and proved to be the most suitable place for the injection.

The $10 \mathrm{ml}$. sampling syringe must be dry and airtight; the piston should move sufficiently freely to be displaced by gas entering the syringe as soon as the needle enters a subcutaneous gas bubble. Massaging the skin to drive bubbles to the needle point is permissible, but suction must not be applied or the sample may be contaminated by air drawn in along the needle track. The first part of the sample is discarded through a two-way tap, the rest is kept in the syringe and finally transferred into a Scholander gas analyser.

\section{RATE OF EQUILIBRATION}

The rate at which the partial pressure of carbon dioxide $\left(\mathrm{pCO}_{2}\right)$ in a subcutaneous gas depot approaches equilibrium with the surrounding tissues is represented by the curve in Fig. 2 . It was constructed from serial estimations in 10 subjects after subcutaneous injection of $50 \mathrm{ml}$. air.

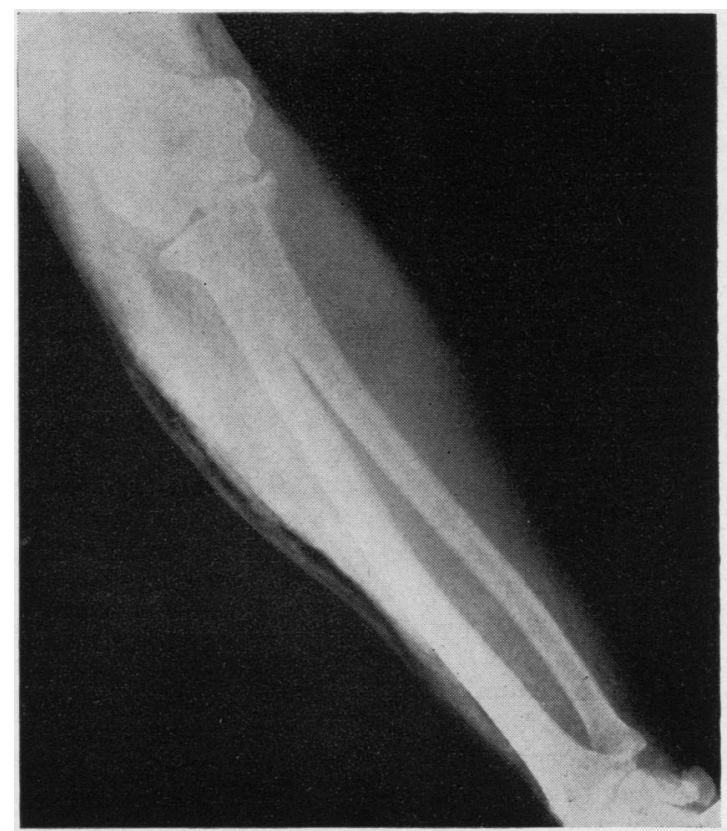

Fig. 1.-Radiograph of a gas reservoir under the skin of the forearm. 


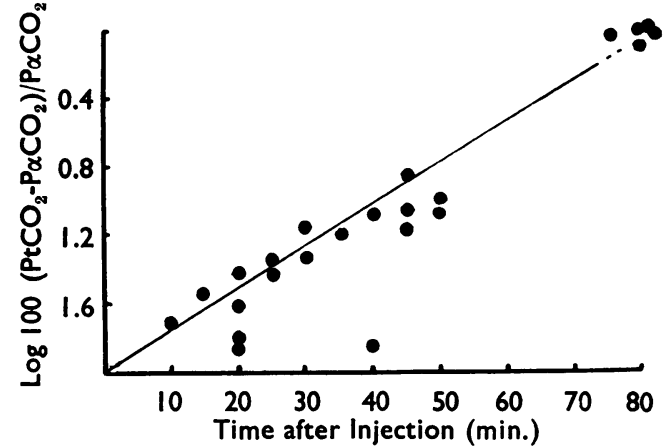

FIG. 2.-Time required for equilibration of a subcutaneous bubble with tissue $\mathrm{CO}_{2}$ tension. Ordinates show the $\log$ of the difference between $\mathrm{CO}_{2}$ tension in the bubble and the final $\mathrm{CO}_{2}$ tension, expressed as a percentage of the latter. (Reproduced by kind permission of the Editor of the Journal of Physiology.)

Complete equilibration was assumed when the $\mathrm{pCO}_{2}$ of two consecutive samples, taken at an interval of 10 minutes, differed by not more than $1 \mathrm{~mm}$. Hg. The intermediate points represent the logarithm of the difference per cent. between the $\mathrm{pCO}_{2}$ at equilibrium and that at stated intervals before equilibrium was reached, as ordinates plotted against time as abscissae.

Equilibration is usually complete at 80 minutes, but the scatter of points shows that in some subjects it has taken longer. This variability probably depends on the size of the individual gas bubbles, since the larger surface area relative to volume favours earlier equilibration in small bubbles. Although the size of the bubbles could not be measured, delayed equilibration was usually observed in subjects in whom relatively large samples were easily withdrawn from presumably large individual gas bubbles.

Comparison of $\mathrm{PCO}_{2}$ in Simultaneous Arterial AND SubCutaneous Samples

The correlation between the partial pressures of carbon dioxide in arterial blood and in subcutaneous gas is shown in Fig. 3. Each point represents the $\mathrm{pCO}_{2}$ in blood and gas samples withdrawn within five minutes of each other. The arterial $\mathrm{pCO}_{2}$ was measured by the method of Riley, Campbell, and Shepard (1957) in 14 subjects and was calculated from the HendersonHasselbalch equation in the remaining two.

The scatter of points around the line representing identical $\mathrm{pCO}_{2}$ values in the two samples may be due to several factors. There are theoretical reasons, confirmed by experimental observations on rats, for assuming that the gas mixture in a subcutaneous gas bubble reflects the partial pressures of gases in venous blood perfusing its boundaries (Rahn and Canfield, 1955 ; Van Liew, $\stackrel{\vec{\rho}}{\stackrel{\bar{P}}{9}}$ 1956). Such a correlation between the $\mathrm{pCO}_{2}$ of $\bar{C}$ subcutaneous gas and arterial blood would be 듬 indicated by a series of points lying to the right of $\bar{T}$ the line, at a horizontal distance representing the arteriovenous $\mathrm{pCO}_{2}$ difference. In fact most points lie to the left of the line, showing that the $\mathrm{pCO}_{2}$ in subcutaneous gas is usually lower than the arterial $\mathrm{pCO}_{2}$.

This unexpected observation is likely to be due to the difference between the temperature of the gas bubbles and that of arterial blood. The studies of Bazett and McGlone (1927) on temperature gradients under the skin of the forearm suggest that this difference is of the order of $1.5^{\circ} \mathrm{C}$. The effect of this is to depress the $\mathrm{pCO}_{2}$ measured in subcutaneous gas $6 \%$ below the expected value, which, but for the temperature difference, would be identical with the $\mathrm{pCO}_{2}$ of venous blood in the forearm. This discrepancy is larger than the arteriovenous $\mathrm{pCO}_{2}$ difference and is sufficient to account for the shift of most points from their expected position to the opposite side of the line.

The effect of temperature on $\mathrm{pCO}_{2}$ is also demonstrated by the results of gas analysis on samples drawn simultaneously from a pneumoperitoneum and a subcutaneous gas depot in three subjects. The three pairs of $\mathrm{pCO}_{2}$ values were 40 and 35,45 and 39,86 and 75 , the higher figure in each case being the $\mathrm{pCO}_{2}$ of peritoneal gas. These differences are too large to be explained by regional variations in the gas content of venous blood and are likely to be due, in part

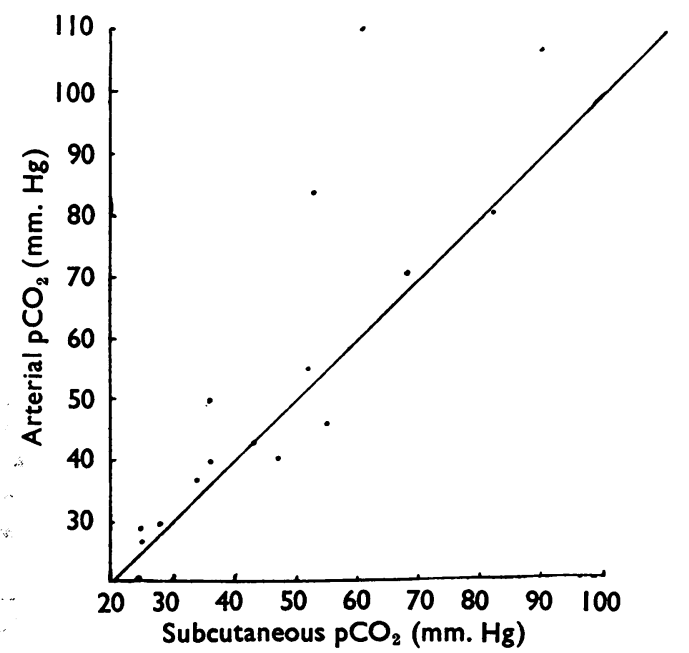

FIG. 3.-Values of $\mathrm{pCO}_{2}$ in subcutaneous gas and arterial blood in samples taken within five minutes of each other. 
at least, to the higher temperature of the peritoneal cavity.

One further reason for variations in the difference between simultaneous arterial and subcutaneous $\mathrm{pCO}_{2}$ values is that the two quantities measured do not stand in a constant relationship to one another. The carbon dioxide content of arterial blood is liable to considerable short-term fluctuations, in contrast to the relative stability of the subcutaneous gas bubbles. A short spell of hyperventilation, for example, lowers the arterial blood carbon dioxide, but it hardly affects the total quantity of this gas dissolved in the tissue fluids. Although it is not possible to produce the opposite effect without a corresponding rise of $\mathrm{pCO}_{2}$ in the tissues, the large quantities of carbon dioxide involved may suddenly accumulate in the body in severe respiratory disease. The subcutaneous gas depot is incapable of rapid adjustment to changes in tissue $\mathrm{CO}_{2}$ tension because of the relatively sluggish gas exchange between the gas bubbles and the surrounding tissue fluids. In the event of a rapid accumulation of $\mathrm{CO}_{2}$ in the tissues, this delay in equilibration may account for the considerably higher $\mathrm{pCO}_{2}$ measured in blood than that in subcutaneous gas.

An example open to this explanation is illustrated in Fig. 3 by the point showing an excess of $40 \mathrm{~mm}$. $\mathrm{Hg}$ in the arterial $\mathrm{pCO}_{2}$ over the subcutaneous gas tension. The samples were taken from a patient under treatment for a head injury, who had a generalized epileptic fit shortly before the arterial blood was withdrawn. The intense muscular activity and apnoea may account for a large retention of carbon dioxide with a concurrent rise of the arterial $\mathrm{pCO}_{2}$, at a time when the slow adjustment of the gas in the subcutaneous bubbles could only just have begun.

The possibility of experimental error as a source of discrepancy between arterial and subcutaneous $\mathrm{pCO}_{2}$ values will be discussed later.

\section{The Normal Range of $\mathrm{PCO}_{2}$ in Subcutaneous Gas}

The partial pressure of $\mathrm{CO}_{2}$ in subcutaneous gas was measured in 10 normal subjects, in three of whom the measurement was repeated on a second occasion. The $\mathrm{pCO}_{2}$ values ranged from 35 to $44 \mathrm{~mm}$. $\mathrm{Hg}$, with a mean of $41 \mathrm{~mm}$. $\mathrm{Hg}$ (S.D.: 2.8). The results obtained in two separate equilibrations on the same subject differed by $1 \mathrm{~mm}$. $\mathrm{Hg}$ in two and by $9 \mathrm{~mm}$. $\mathrm{Hg}$ in one.

The long-term stability of the $\mathrm{pCO}_{2}$ in the tissues was studied in peritoneal gas samples drawn at weekly intervals from five patients under treatment with a pneumoperitoneum for localized pulmonary tuberculosis. The results of these measurements, summarized in Table I, show little variation over a period of several weeks. The

TABLE I

CARBON DIOXIDE TENSIONS IN PERITONEAL GAS SAMPLES TAKEN AT WEEKLY INTER VALS FROM FIVE PATIENTS WITH THERAPEUTIC PNEUMOPERITONEUM

\begin{tabular}{|c|c|c|c|c|c|}
\hline \multirow[b]{2}{*}{$\begin{array}{l}\text { Case } \\
\text { No. }\end{array}$} & \multirow[b]{2}{*}{$\begin{array}{c}\text { No. of } \\
\text { Estima- } \\
\text { tions }\end{array}$} & \multicolumn{4}{|c|}{$\mathrm{pCO}_{2}(\mathrm{~mm} . \mathrm{Hg})$} \\
\hline & & Range & Mean & S.D. & $\begin{array}{c}\text { Coefficient } \\
\text { of } \\
\text { Variation } \\
(\%)\end{array}$ \\
\hline $\begin{array}{l}1 \\
2 \\
3 \\
4 \\
5\end{array}$ & $\begin{array}{r}5 \\
11 \\
8 \\
9 \\
4\end{array}$ & $\begin{array}{l}52-57 \\
39-48 \\
42-49 \\
45-49 \\
40-42\end{array}$ & $\begin{array}{l}54 \cdot 6 \\
44.4 \\
45.9 \\
48.0 \\
41.5\end{array}$ & $\begin{array}{l}2.46 \\
2.18 \\
2.40 \\
1.41 \\
1.22\end{array}$ & $\begin{array}{l}4.5 \\
4.9 \\
5.0 \\
2.9 \\
2.9\end{array}$ \\
\hline
\end{tabular}

higher mean $\mathrm{pCO}_{2}$ value of peritoneal gas (47 $\mathrm{mm}$. $\mathrm{Hg}$ ), compared with the mean subcutaneous $\mathrm{pCO}_{2}(41 \mathrm{~mm}$. $\mathrm{Hg})$, is probably due to the temperature difference, as previously noted.

\section{Clinical Applications}

Subcutaneous gas equilibration has now been performed on over 200 occasions, mainly on patients with chronic respiratory diseases. The lowest $\mathrm{pCO}_{2}(24 \mathrm{~mm}$. $\mathrm{Hg})$ was observed in a woman with tetany due to hysterical hyperventilation, and the highest $\mathrm{pCO}_{2}(105 \mathrm{~mm}$. $\mathrm{Hg})$ in a man with chronic bronchitis during an acute respiratory infection. Single measurements, repeated at intervals of several months, provided an informative record of the progress of patients with failing ventilation. These data were of particular value as a background against which recovery from intercurrent lung infections could be objectively assessed.

One example of the way in which serial measurements of the subcutaneous $\mathrm{pCO}_{2}$ may be applied in clinical practice is illustrated by Fig. 4 . The graph shows the fluctuations of $\mathrm{pCO}_{2}$ during a protracted lung infection complicating chronic respiratory failure. The points marked $V_{1}, V_{2}$, and $V_{3}$ represent three periods of 30 minutes during which ventilation was assisted by positive pressure transmitted through a demand valve. Measurements of $\mathrm{pCO}_{2}$ one hour before and one hour after this treatment showed a fall of $13 \mathrm{~mm}$. $\mathrm{Hg}$ on the first occasion, a rise of $7 \mathrm{~mm}$. $\mathrm{Hg}$ on the second, and a fall of $6 \mathrm{~mm} . \mathrm{Hg}$ on the third occasion. Ventilation was assisted with the same apparatus for 20 minutes every four hours for 


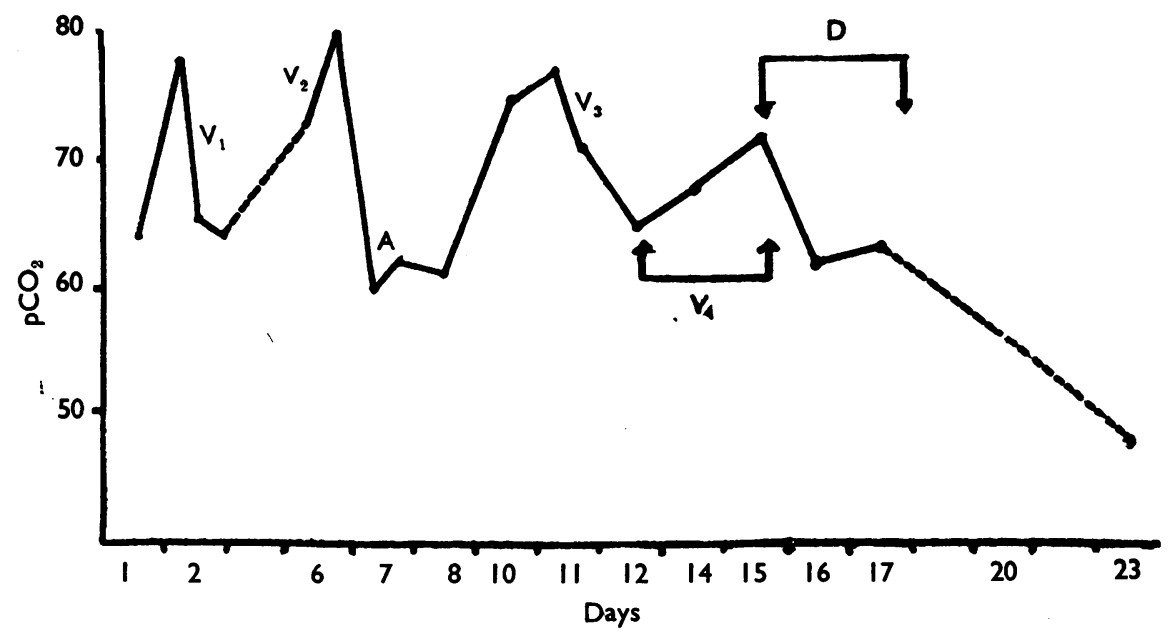

Fig. 4. Serial subcutaneous $\mathrm{pCO}_{2}$ measurements during an acute lung infection complicating chronic bronchitis. Assisted ventilation at $\mathrm{V}_{1,2,3,4}$. Administration of oxygen interrupted at $A$. Acetazoleamide given at $\mathbf{D}$.

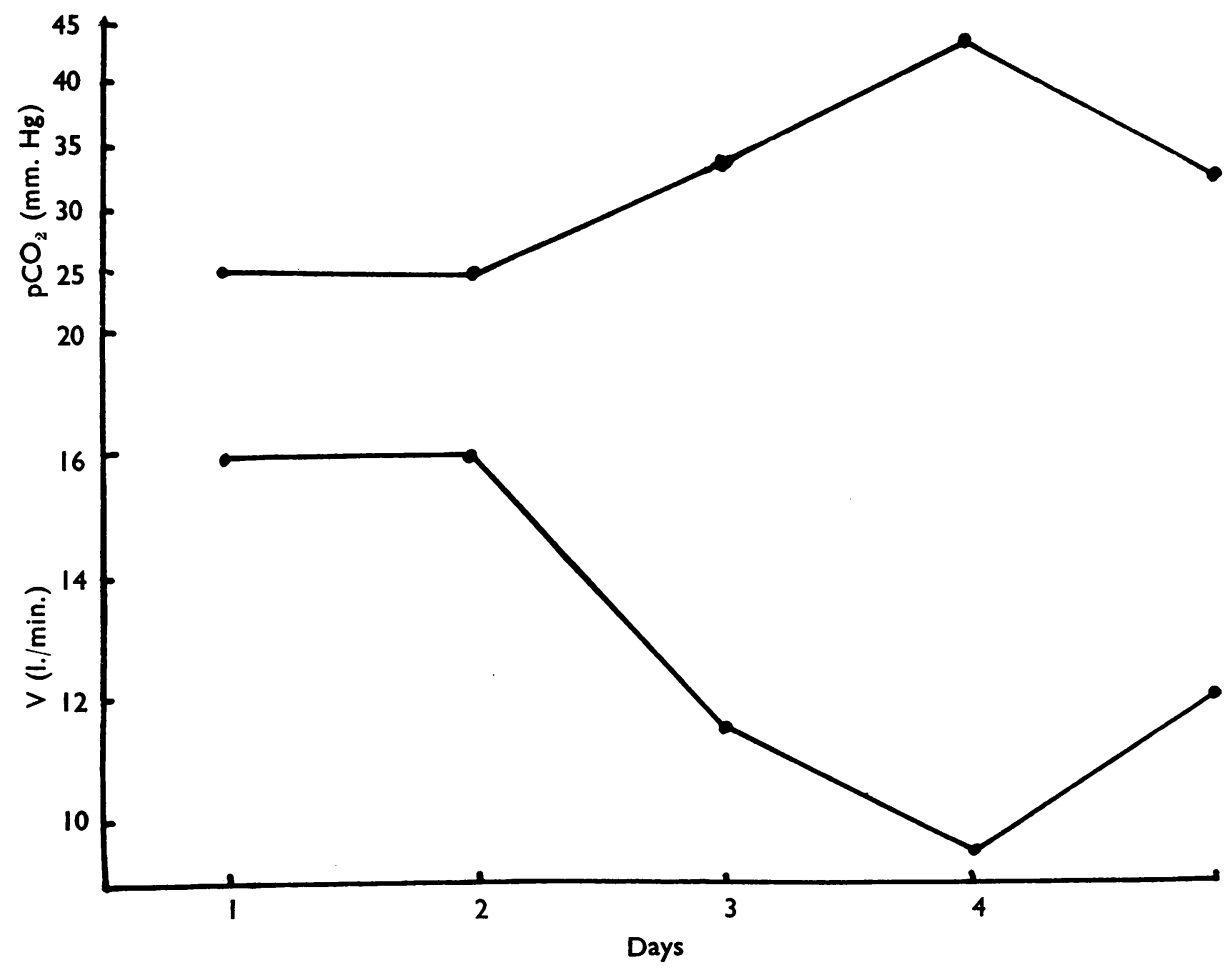

FIG. 5. - Minute volume and corresponding subcutaneous $\mathrm{pCO}_{2}$ values during positive pressure ventilation. 
three days, indicated on the chart by $\mathrm{V}_{4}$. During this period the $\mathrm{pCO}_{2}$ rose by $7 \mathrm{~mm}$. $\mathrm{Hg}$. Breathing air instead of $100 \%$ oxygen for two and a half hours (at point $A$ ) resulted in severe anoxia and a rise of $\mathrm{pCO}_{2}$ by $2 \mathrm{~mm}$. $\mathrm{Hg}$. The administration of acetazoleamide, $1 \mathrm{~g}$. daily, for three days (marked $D$ ), coincided with a considerable fall in the $\mathrm{pCO}_{2}$ values, but the need for caution in attributing this improvement to the drug is illustrated by the even larger spontaneous fall of the $\mathrm{pCO}_{2}$ at an earlier stage of the illness. Recovery from the infection and a gradual return of the $\mathrm{pCO}_{2}$ to a level slightly above normal takes place during the fourth week.

The correct setting of automatically cycled breathing apparatus in the treatment of respiratory paralysis, head injuries, and other respiratory emergencies depends on the repeated measurement of $\mathrm{CO}_{2}$ tension in arterial blood, alveolar gas, or tissue fluids ; the use of serial subcutaneous $\mathrm{pCO}_{2}$ estimations of the latter for this purpose is shown in Fig. 5. The tracing illustrates the correlation between the ventilation and the $\mathrm{pCO}_{2}$ values in a patient under treatment for multiple bilateral fractures of the ribs and laceration of the lung. There was extensive surgical emphysema of the chest wall, providing unlimited supplies of subcutaneous gas for carbon dioxide estimations. The volume of air delivered by the positive pressure apparatus was gradually adjusted to the correct value in the light of repeated estimations of the subcutaneous $\mathrm{pCO}_{2}$.

\section{Discussion}

The methods in current use by which the adequacy of alveolar ventilation is measured are based upon the estimation of the partial pressure of carbon dioxide in arterial blood or alveolar gas. Samples drawn from either of these sources may, however, yield an unduly low estimate of the dissolved $\mathrm{CO}_{2}$ stores of the body if ventilation, relative to pulmonary blood flow, happens to be temporarily raised at the time of sampling. Although minor transient changes in excretion hardly affect the large carbon dioxide stores of the whole body, a large excess of $\mathrm{CO}_{2}$, amounting to several litres of gas, may raise their level considerably above the average value. As shown by an example given earlier, acute $\mathrm{CO}_{2}$ retention of this magnitude may occur during violent muscular activity in patients with severely impaired ventilation.

It seems illogical to judge the average level of the free $\mathrm{CO}_{2}$ stores in clinical practice by samples drawn from arterial blood or from the alveoli, where the partial pressure of this gas is liable to the largest fluctuations. Measurement of the amount of $\mathrm{CO}_{2}$ dissolved in the tissues, as reflected by the $\mathrm{pCO}_{2}$ of mixed venous blood or rebreathed alveolar gas, is more likely to yield a representative value and is therefore better suited to clinical assessment of the adequacy of ventilation. The nearest approach to a steady value is, however, represented by the $\mathrm{CO}_{2}$ content of subcutaneous gas, where the relatively slow exchange between tissue fluids and gas bubbles irons out even those short-term variations which may affect the $\mathrm{CO}_{2}$ stores of the body in an unsteady state.

These theoretical considerations are not sufficient to justify the clinical use of the method under discussion unless it also satisfies such practical conditions as safety, reasonable freedom from error in sampling and estimation, technical simplicity, and the comfort of the patient.

Samples drawn from a subcutaneous gas reservoir may become contaminated by air leaks along the needle track. Estimations on simultaneously withdrawn duplicate samples have shown contamination to be unlikely if the technical recommendations for sampling are observed. Incomplete equilibration as a source of error has already been considered. As a safeguard two consecutive samples may be taken at an interval of 15 minutes, and checked for identity of $\mathrm{CO}_{2}$ content. This precaution is applicable when the gas reservoir is tapped soon after the minimum period of 80 minutes required for equilibration, especially if the gas has not broken up into small bubbles but has remained in one large compartment.

The observation that cooling of the skin results in an underestimate of the partial pressure of carbon dioxide in the tissues has already been reported by Bazett and Sribyatta (1928). This source of error constitutes the most serious disadvantage of the method. Control of the skin temperature is possible, but it introduces complications which would make the technique too cumbersome for clinical use. It seems preferable to take simple precautions against cooling, and to ascertain by touch that the skin is warm. In such circumstances the subcutaneous $\mathrm{pCO}_{2}$ value remains close enough to that of arterial blood for reasonably accurate clinical measurements.

There remains the theoretical possibility of a local accumulation of carbon dioxide due to excessive muscular activity or reduction of blood flow. In practice this can be avoided by ensuring that the limb is not used excessively during 
equilibration and is not constricted by clothing or bandages.

The estimation of the $\mathrm{CO}_{2}$ content of a gas mixture is easier and more accurate than any of the methods in current use by which the $\mathrm{pCO}_{2}$ in blood is measured. From the patient's point of view there is little to choose between the discomfort of a single arterial puncture and the withdrawal of subcutaneous gas, but for oftenrepeated sampling the latter is clearly preferable. Finally, the risk of air embolism during the injection must be considered. It has not occurred in our patients, nor has it been recorded by others in their experiments on animals and man. With the small volumes of air injected, the risk is likely to be negligible.

\section{Summary}

Subcutaneous injection of air creates a gas reservoir which lends itself to repeated sampling and measurement of the partial pressure of carbon $\overrightarrow{\overrightarrow{\vec{S}}}$ dioxide in the surrounding tissues. Application of $\overline{0}$ this method to the management of patients with $\frac{\mathrm{C}}{\mathrm{C}}$ failing ventilation gave clinically useful results. के The subcutaneous $\mathrm{pCO}_{2}$ values are close to but $\mathrm{\Phi}$ more stable than the $\mathrm{pCO}_{2}$ of arterial blood. Undue cooling of the skin during equilibration ${ }^{\infty}$ may, however, lead to a serious underestimate of $\vec{O}$ the free carbon dioxide stores.

\section{REFERENCES}

Bazett, H. C., and McGlone, B. (1927). Amer. J. Physiol., 82, 415. and Sribyatta, L. (1928). Ibid., 86, 565.

Campbell, J. A. (1931). Physiol. Rev., 11, 1.

Leconte, C., and Demarquay, J. (1859). Arch. gén. Med., 5 ser., 14,w 424.

Meyer, F. (1935). Arch. exp. Path. Pharmak., 177, 693.

Rahn, H., and Canfield, R. E. (1955). WADC Technical Report, 55-357, 395.

Riley, R. L., Campbell, E. J. M., and Shepard, R. H. (1957). J. appl. Physiol., 11, 245.

Seevers, M. H. (1936). Amer. J. Physiol., 115, 38.

Van Liew, H. D. (1956). WADC Technical Report, 56-466, 60. 